
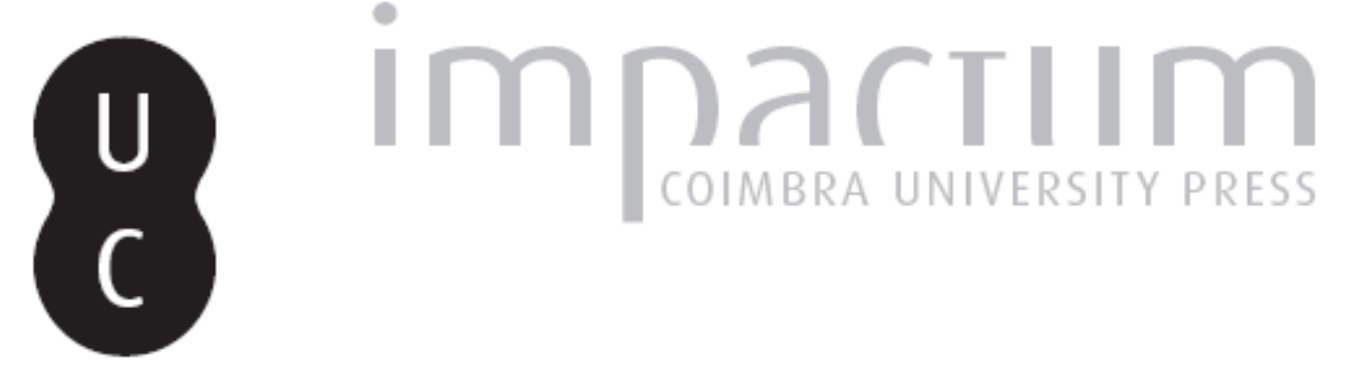

O "paroxismo" pluviométrico de 2000/2001 em Coimbra: umas notas a montante dos riscos naturais e da crise

Autor(es): $\quad$ Ganho, Nuno

Publicado por: Associação Portuguesa de Riscos, Prevenção e Segurança

URL persistente:

URI:http://hdl.handle.net/10316.2/40083

DOI:

DOI:https://doi.org/10.14195/1647-7723_9_1

Accessed : $\quad$ 26-Apr-2023 14:44:41

A navegação consulta e descarregamento dos títulos inseridos nas Bibliotecas Digitais UC Digitalis, UC Pombalina e UC Impactum, pressupõem a aceitação plena e sem reservas dos Termos e Condições de Uso destas Bibliotecas Digitais, disponíveis em https://digitalis.uc.pt/pt-pt/termos.

Conforme exposto nos referidos Termos e Condições de Uso, o descarregamento de títulos de acesso restrito requer uma licença válida de autorização devendo o utilizador aceder ao(s) documento(s) a partir de um endereço de IP da instituição detentora da supramencionada licença.

Ao utilizador é apenas permitido o descarregamento para uso pessoal, pelo que o emprego do(s) título(s) descarregado(s) para outro fim, designadamente comercial, carece de autorização do respetivo autor ou editor da obra.

Na medida em que todas as obras da UC Digitalis se encontram protegidas pelo Código do Direito de Autor e Direitos Conexos e demais legislação aplicável, toda a cópia, parcial ou total, deste documento, nos casos em que é legalmente admitida, deverá conter ou fazer-se acompanhar por este aviso.

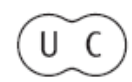




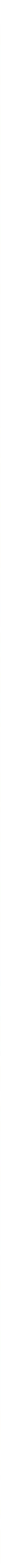




\title{
O "paroxismo" pluviométrico de 2000/2001 em Coimbra. Umas notas a montante dos riscos naturais e da crise
}

\author{
Nuno Ganho*
}

\section{Resumo:}

Neste artigo, analisam-se parâmetros pluviométricos ocorridos no semestre de Outubro-Março de 2000/2001, em Coimbra, no contexto dos seus regimes médios e prováveis, atribuindo uma objectividade quantitativa ao paroxismo climático que caracterizou este período em Portugal Continental.

Palavras chave:

Riscos climáticos, paroxísmo pluviométrico, Coimbra.

\section{Résumé:}

Dans cet article, on analyse des paramètres pluviometriques du semestre d'Octobre-Mars 2000/2001, dans la ville de Coimbra, dans le contexte de leurs régimes moyens et probables, en attribuant une objectivité quantitative au paroxisme climatique qui a caracterisé cette période au Portugai continental.

Mots clés:

Risques climatiques, paroxisme pluviometrique, Coimbra.

\section{Abstract:}

In this paper we analyse pluviometric parameters of the semestre October-March 2000/2001, in the town of Coimbra, in the context of their average and probable regimes, giving a quantitative objectivity to the climatic paroxism that caracterized this period in continental Portugal.

Key words:

Climatic hazards, pluviometric paroxism, Coimbra.

\section{Introdução}

O semestre de Outubro a Março de 2000/2001 caracterizou-se por quantitativos pluviométricos particularmente elevados, um pouco por todo o território continental de Portugal, com consequências fortemente sentidas pelas populações e amplamente veiculadas pelos meios de comunicação social, porque algumas com graves danos materiais e pessoais - movimentações de vertentes, cheias e inundações, disseminadas por vários locais do país e, em alguns destes locais, reincidentes em curtos espaços de tempo - e que foram já, per se, objecto de estudo por parte de especialistas em questões ligadas à geocindínica

\footnotetext{
* Instituto de Estudos Geográficos e Centro de Estudos Geográficos,
} Faculdade de Letras, Universidade de Coimbra.
(F.REBELO, 2001; A. ALVES, 2001; L. LOURENÇO e L. LEMOS, 2001; A. PEDROSA, L. LOURENÇO e J. FELGUEIRAS, 2001; J. LEMOS, L. LOURENÇO e C. GONÇALVES, 2001, entre outros).

Mas, perante a crise impõe-se, também, um estudo das causas a montante, de origem meteorológica e inseridas num contexto de probabilidades e risco climático, inerentes às características dos climas de "transição" como é, à escala mesoclimática, o de Portugal, com grande variabilidade pluviométrica interanual.

Na impossibilidade prática de, "tão em cima dos acontecimentos", completar um estudo causal (necessariamente de base sinóptica) e à escala de todo o território, do carácter das precipitações "invernais" de 2000/2001, apresentam-se umas notas sobre os valores de diversos parâmetros pluviométricos 
observados, neste período, em Coimbra, na estação meteorológica do Instituto Geofísico da Universidade (IGU), a sua comparação com os regimes ditos "normais" e contex tualização nos regimes prováveis. Por outras palavras e em linguagem comum, tenta-se responder, com o rigor e a aparente simplicidade dos números, a questões que se resumem numa só e tantas vezes ouvida até meados do ano de 2001: "mas afinal vivemos oinverno mais chuvoso de que há memória?".

\section{Aspectos metodológicos}

Com base nos registos efectuados na estação meteorológica do IGU ${ }^{(1)}$, calculou-se a precipitação acumulada mensalmente e o correspondente número de dias, por mês, em que ocorreu precipitação. Os meses de Setembro e de Outubro de 2000 acumularam, respectivamente, 57.4 e $105.4 \mathrm{~mm}$ de precipitação, ocorrida em 4 dias de Setembro e em.11 dias de Outubro. O ano hidrológico de 2000/2001 começou, assim, com valores de precipitação muito próximos dos valores ditos "normais" calculados para o período de 1961-90 na estação meteorológica do IGU, e que são de 48.2 e de $98.9 \mathrm{~mm}$ de precipitação média em Setembro e Outubro, respectivamente (N. GANHO, 1998, p. 136). Em Abril e Maio de 2001 registaram-se, no IGU, 40.8 e $70.2 \mathrm{~mm}$ de precipitação, acumulada, em ambos os meses, em 8 dias, valores que, quando comparados com os valores médios "normais" para o período de referência de 1961-1990 (N. GANHO, 1998, p. 136), são ligeiramente inferiores para o mês de Maio $(78.0 \mathrm{~mm})$ e menos de metade para o mês de Abril (91.2mm). O "paroxísmo" pluviométrico de $2000 / 2001$, restringe-se, por isso, ao período correspondente aos meses de Novembro de 2000 a Março de 2001, não obstante, ao mês de Fevereiro de 2001 corresponder um valor de precipitação acumulada de $123.4 \mathrm{~mm}$, ligeiramente aquém do valor médio "normal" para o período de 1961-90, queé de $140.3 \mathrm{~mm}$. Assim se justifica que os dados em que se alicerça a análise apresentada no presente trabalho correspondam sempre ao șemestre de Outubro de 2000 a Março de 2001, período durante o qual, a precipitação acumulada no IGU foi extremamente elevada, na sequência de um, também, muito grande número de dias de precipitação.

Do ponto de vista metodológico, para este semestre Outubro-Março 2000/2001, mês a mês, comparam-se os valores de precipitação acumulada (0-24h), do número de dias de precipitação, da precipitação máxima em 24 h e da precipitação máxima em 1 h,

(1) Os meus agradecimentos ao Dr. António José Alves, do Instituto Geofísico da Universidade de Coimbra, que gentil e prontamente me cedeu todos os dados das variáveis climáticas analisadas neste trabaho. com os valores médios calculados para o período de 1961-90, ditos "normais", ou com os valores máximos extremos de uma série secular, correspondente a 1891-1990, ou ainda com os regimes prováveis destas mesmas variáveis, calculados com, base na mesma série secular de 1891-1990. Por estes terem sido já objecto de um estudo anterior (N. GANHO, 1998) e por isso, encontrando-se já previamente definidos, permitem que agora se façam comparações, mas restringem as comparações à estação meteorológica do IGU, dado que, para outras estações meteorológicas não existem, por ora, estudos contemplando exactamente a mesma metodologia para, rigorosamente, a mesma série secular.

\section{Caracterização da sequência pluviosa de Outubro a Março de 2000/2001}

O histograma da figura 1 mostra os quantitativos pluviométricos diários, acumulados entre as 0 e as 24h, no IGU, de 1 de Outubro de 2000 a 31 de Março de 2001 e o quadro 1 sistematiza as sequências de dias "com"e "sem" precipitação, neste mesmoperíodo, os correspondentes quantitativos de precipitação acumulada em cada sequência de dias pluviosos e a precipitação média diária obtida para cada sequência de dias de chuva.

Tal como foi anteriormente referido, não tendo sido o mês de Outubro de 2001 muito chuvoso, o início da sequência particularmente pluviosa corresponde aodia 2 de Novembrode 2000 , estendendose até ao dia 9 de Fevereiro de 2001, altura em que é interrompida por uma série de dias sem precipitação ou de precipitação pouco significativa, até 27 de Fevereiro, altura em que se inicia nova sequência pluviosa que só termina a 30 de Março de 2001 (fig. 1). Neste período de 182 dias, em 120 dias ocorreu precipitação (quadro 1). As subsequências de dias seguidos de chuva, mais longas, foram de 19 dias entre 20 de Dezembro e 7 de Janeiro, de 15 dias entre 26 de Fevereiro e 12 de Março e de 13 dias entre 28 de Novembro e 10 de Dezembro, e entre 18 e 30 de Março. As restantes sequências de dias de precipitação foram inferiores a 10 dias. Note-se porém que, frequentemente, as sequências de dias com precipitação são interrompidas apenas por 1, 2 ou 3 dias seguidos sem precipitação o que, tendo chovido muito e durante muito tempo antes, pouco significado terá do ponto de vista hidrogeomorfológico em geral e do funcionamento hidrológico subterrâneoem particular, com efeitos cumulativos na geodinâmica externa e, consequentemente, no potenciar dos riscos naturais. Somente entre 10 e 22 de Fevereiro a sequência de 13 dias sem precipitação poderá ter significado geocindínico. Grande importância tềm, certamente, 
os quantitativos pluviométricos médios diários das mais longas sequências de dias de precipitação (quadro 1). Entre 22 e 28 de Janeiro, numa sequência não muito longa, de apenas 7 dias, acumularam-se $184.7 \mathrm{~mm}$ de precipitação, correspondendo-lhe a média diária mais elevada, de $26.4 \mathrm{~mm}$. Segue-se-lhe, em importância de "intensidade" de precipitação, a sequência de 4 a 9 de Fevereiro (6 dias) em que a precipitação acumulada foi de $104.3 \mathrm{~mm}$, o que corresponde a uma precipitação média diária de $17.4 \mathrm{~mm}$. Às já referidas sequências mais longas, nomeadamente de 19 dias (20 de Dezembro a 7 de Janeiro) e de 13 dias (de 28 de Novembro a 10 de Dezembro), durante as quais a precipitação acumulada foi de $253.0 \mathrm{~mm}$ e de $179.4 \mathrm{~mm}$, respectivamente, a "intensidade" média diária da precipitação rondou os $13 \mathrm{~mm}$, o mesmo que na série de 7 dias, entre 2 e 8 de Novembro, mas mais significativa do que na longa sequência de 15 dias pluviosos, entre 26 de Fevereiroe 12 de Março, em que o total acumulado foi de $149.2 \mathrm{~mm}$ e a precipitação média diária de $10.0 \mathrm{~mm}$, ou na série de 13 dias, entre 18 e 30 de Março, em que o cumulativo pluviométrico foi, apenas, de $72.5 \mathrm{~mm}$ e a média diária, por isso, somente de $5.6 \mathrm{~mm}$. Porém, a quantidade total de precipitação
Quadro I - Sequências de dias "com" e "sem" precipitação, no período de Outubro a Março de 2000/2001, em Coimbra (IGU)

\begin{tabular}{|c|c|c|c|c|}
\hline $\begin{array}{r}\text { dias COM } \\
\text { Precipitação } \\
\end{array}$ & $\begin{array}{l}\text { dias SEM } \\
\text { Precipitaçäo } \\
\end{array}$ & Dia/Período & $\begin{array}{c}\text { Quantidade } \\
\text { Precipitação (mm) } \\
\end{array}$ & $\begin{array}{l}\text { Precipitaçâo média } \\
\text { diária (mIm) }\end{array}$ \\
\hline 1 & & 10ut & 2.9 & 2.9 \\
\hline 4 & & 9-12Out & 43.6 & 10.9 \\
\hline 2 & & 14-150ut & 5.2 & 2.6 \\
\hline 2 & & 19-200ul & 31.9 & 16.0 \\
\hline 1 & & 280ut & 2.4 & 2.4 \\
\hline 1 & & 30Out & 19.4 & 19.4 \\
\hline 7 & & 2-8Nov & 97.6 & 13.9 \\
\hline 5 & & $12.16 \mathrm{Nov}$ & 39.7 & 7.9 \\
\hline 8 & & 19-2 Nov & 67.2 & 8.4 \\
\hline 13 & & 28Nov-10Dez & 179.4 & 13.8 \\
\hline 3 & & 12-14Dez & 29.3 & 9.8 \\
\hline 1 & 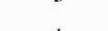 & 18Dez & 0.7 & 0.7 \\
\hline 19 & & 20Dez-7Jan & 253.0 & 13.3 \\
\hline 4 & 7 & $9-123 \mathrm{an}$ & 36.9 & 9.2 \\
\hline 5 & ר & 15-19Jan & 20.5 & 4.1 \\
\hline 7 & 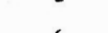 & 22-28Jan & 184.7 & 26.4 \\
\hline 6 & 13 & 4-9Fev & 104.3 & 17.4 \\
\hline 2 & & 23-24Fev & 2.1 & 1.1 \\
\hline 15 & & $26 \mathrm{Fev}-12 \mathrm{Mar}$ & 149.2 & 10.0 \\
\hline 1 & & loMar & 22.8 & 22.8 \\
\hline 13 & 1 & 18-30Mar & 72.5 & 5.6 \\
\hline Total $=120$ & Total $=62$ & & Tolal $=1365.3$ & \\
\hline
\end{tabular}

Prec. $0-24 \mathrm{~h} \mathrm{~mm}$

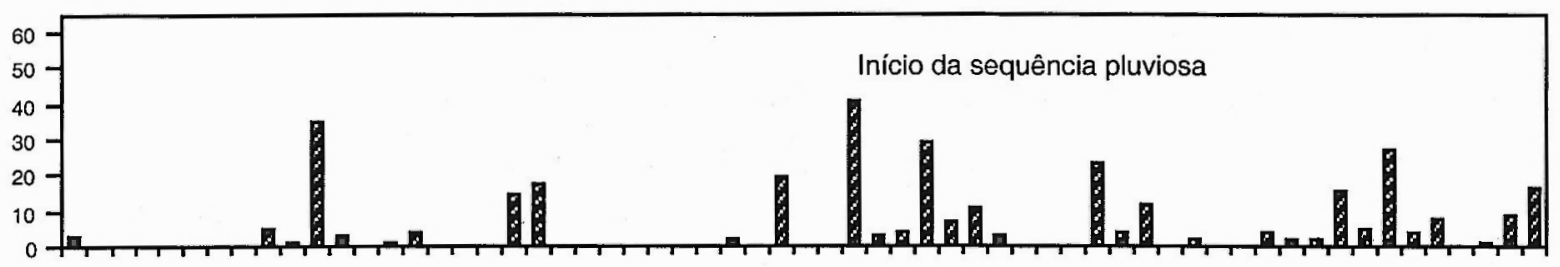

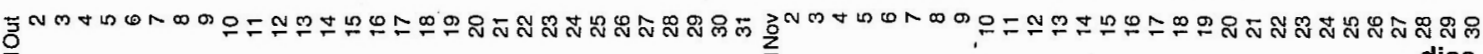
Prec. $0-24 \mathrm{~h} \mathrm{~mm}$

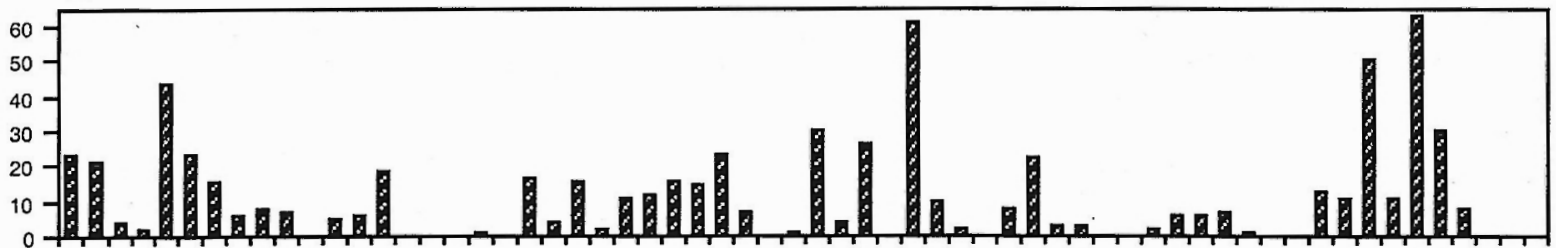

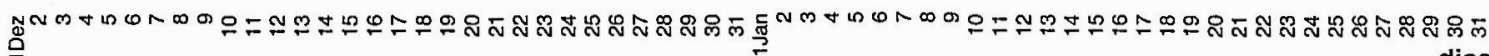

Prec. $0-24 \mathrm{~h} \mathrm{~mm}$

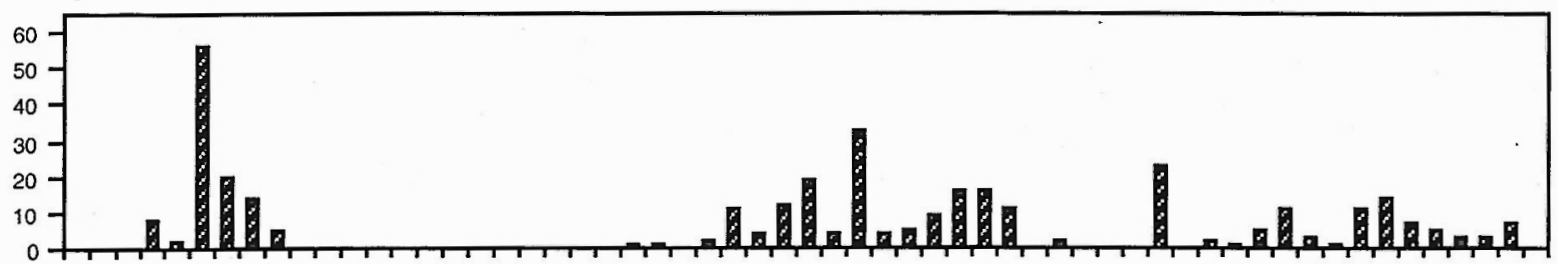

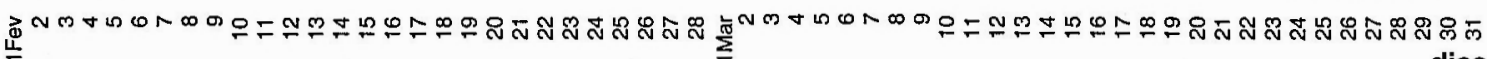

Fig. 1 - Precipitação diária acumulada (0-24h), de 1 de Outubro de 2000 a 31 de Março de 2001 em Coimbra (IGU) 
registada no conjunto dos 182 dias do semestre de 1 de Outubro de 2000 a 31 de Março de 2001, foi de $1365.3 \mathrm{~mm}$, valor muito elevado no contexto dos regimes pluviométricos médio e provável no IGU, como adiante se demonstrará.

\section{Contextualização do semestre Outubro-Março 2000/2001 relativamente ao regime pluvio- métrico "normal" eaos máximos pluviométricos extremos seculares}

Quando comparados os valores pluviométricos "brutos" anteriormente comentados, com os valores mensais "médios" relativos ao período 1961-90, ou com os máximos mensais extremos registados no período centenário de 1891-1990, no IGU, consegue atribuir-se uma dimensão relativa à quantidade $\mathrm{e}$ intensidade das precipitações ocorridas entre Outubro de 2000 e Março de 2001. Ou seja, contextualizam-se os parâmetros pluviométricos mensais deste semestre nos regimes "normais" e extremos, como testemunha o quadro 2 .
Assim, relativamente à precipitação mensal acumulada, o mês mais pluvioso foi Janeiro, com $374.7 \mathrm{~mm}$, seguido de Dezembro, com $303.4 \mathrm{~mm}$. Novembro e Março acumularam valores de precipitação muito próximos entre si, respectivamente de $230.9 \mathrm{e} 227.5 \mathrm{~mm}$. Em qualquer um destes meses a precipitação ocorrida foi muito superior ao valor médio do período de 1961-90. O maior valor relativo corresponde a Janeiro, com uma precipitação $272 \%$ superior ao valor "normal", logo seguido por Março com $260 \%$ e de Dezembro com um excedente pluviométrico de $235 \%$ relativamente ao "normal". Tanto Outubro como Novembro foram também meses excedentários relativamente à precipitação média de 1961-90, respectivamente com valores relativos de 107 e $181 \%$, o que não deixa de ser significativo. A única excepção, no contexto deste semestre chuvoso, é o mês de Fevereiro, em que a precipitação acumulada foi inferior à "normal", correspondendo a $88 \%$ da média do período de referência. O total pluviométrico semestral acumulado, de $1365.3 \mathrm{~mm}$, corresponde a quase o dobro (189\%) da precipitação que em média ocorre neste conjunto de meses.

\begin{tabular}{|c||c|c|c|c|c|c|c|}
\hline $\begin{array}{c}\text { Prec. acum. } \\
\text { 0-24h, mm }\end{array}$ & Out & Nov & Dez & Jan & Fev & Mar & Out-Mar \\
\hline \hline $\mathbf{2 0 0 0 / 2 0 0 1}$ & 105.4 & 230.9 & 303.4 & 374.7 & 123.4 & 227.5 & 1365.3 \\
média 1961-90 & 98.9 & 127.4 & 129.1 & 137.7 & 140.3 & 87.5 & 720.9 \\
Desvio (mm) & 6.5 & 103.5 & 174.3 & 237.0 & -16.9 & 140.0 & 644.4 \\
Valor relativo (\%) & 107 & 181 & 235 & 272 & 88 & 260 & 189 \\
\hline
\end{tabular}

\begin{tabular}{|c||c|c|c|c|c|c|c|}
\hline $\begin{array}{c}\text { Prec. } \\
\mathbf{n}^{\mathbf{0}} \text { dias }\end{array}$ & Out & Nov & Dez & Jan & Fev & Mar & Out-Mar \\
\hline \hline $2000 / 2001$ & 11 & 23 & 26 & 23 & 11 & 26 & 120 \\
média 1961-90 & 13 & 14 & 15 & 16 & 15 & 14 & 87 \\
Desvio (n dias) & -2 & 9 & 11 & 7 & -4 & 12 & 33 \\
Valor relativo (\%) & 84 & 164 & 173 & 144 & 73 & 186 & 138 \\
\hline
\end{tabular}

\begin{tabular}{|c||c|c|c|c|c|c|c|}
\hline $\begin{array}{c}\text { Prec. máx. } \\
\text { 24h, mm }\end{array}$ & Out & Nov & Dez & Jan & Fev & Mar & Out-Mar \\
\hline \hline $\mathbf{2 0 0 0 / 2 0 0 1}$ & 34.8 & 40.8 & 43.8 & 62.6 & 55.9 & 32.9 & 62.6 \\
máx. 1891-1990 & 92.1 & 108.0 & 93.1 & 76.0 & 56.8 & 55.0 & 122.7 \\
(a no) & $(1913)$ & $(1963)$ & $(1989)$ & $(1941)$ & $(1972)$ & $(1897)$ & $($ Set. 1936) \\
Desvio (mm) & -57.3 & -67.4 & -49.3 & -13.4 & -0.9 & -22.1 & -60.1 \\
Valor relativo (\%) & 38 & 38 & 47 & 82 & 98 & 60 & 51 \\
\hline
\end{tabular}

\begin{tabular}{|c||c|c|c|c|c|c|c|}
\hline $\begin{array}{c}\text { Prec. máx. } \\
\text { 1h, mm }\end{array}$ & Out & Nov & Dez & Jan & Fev & Mar & Out-Mar \\
\hline \hline $\mathbf{2 0 0 0 / 2 0 0 1}$ & 9.0 & 15.1 & 11.1 & 13.2 & 17.7 & 12.4 & 17.7 \\
máx. 1891-1990 & 32.8 & 29.3 & 26.0 & 18.6 & 21.7 & 20.4 & 43.0 \\
(ano) & $(1953)$ & $(1940)$ & $(1915)$ & $(1955)$ & $(1978)$ & $(1943)$ & $($ Jun. 1950) \\
Desvio (mm) & -23.8 & -14.2 & -14.9 & -5.4 & -4.0 & -8.0 & 25.3 \\
Valor relativo (\%) & 27 & 52 & 43 & 71 & 82 & 61 & 41 \\
\hline
\end{tabular}

Quadro 2 - Desvios pluviométricos do semestre Outubro-Março de 2000/2001 relativamente às médias "normais" do período 1961-90, ou aos máximos extremos da série secular de referência 1891-1990, em Coimbra (IGU) 
Quantidades de precipitação tão elevadas foram acumuladas ao longo de um grande número de dias, num total de 26 em Dezembro e Março, e de 23 em Novembro e Janeiro, bastante superior ao número "normal" de dias de chuva: Março com um valor relativo de $186 \%$, Dezembro com $173 \%$, Novembro com $164 \%$ e Janeiro com $144 \%$. Só em Outubro e em Fevereiro o número de dias com precipitação foi inferior à média de 1961-90, ficando-se pelos $84 \mathrm{e}$ $73 \%$ do "normal", respectivamente. Os 120 dias com ocorrência de precipitação entre 1 de Outubro de 2000 e 31 de Março de 2001, correspondem a um excedente de $138 \%$ relativamente ao número médio de dias pluviosos neste semestre, calculados com base no período de 1961-90.

Atente-se agora não nas quantidades mas nas intensidades das precipitações (quadro 2).

A precipitação máxima ocorrida em $24 \mathrm{~h}$ foi de $62.6 \mathrm{~mm}$ em Janeiro, $55.9 \mathrm{~mm}$ em Fevereiro, de 43.8 e $40.8 \mathrm{mmem}$ Dezembro e Novembro, respectivamente, e de $34.8 \mathrm{~mm}$ em Outubro e $32.9 \mathrm{~mm}$ em Março. Valores significativos para precipitaçães diárias, mas, em qualquer dos casos, aquém dos máximos extremos ocorridos no período secular de referência de 1891-1990. Só o valor correspondente ao mês de Fevereiro se aproximou do recorde do respectivo mês (valor relativo de $98 \%$ ). Os $62.6 \mathrm{~mm}$ em $24 \mathrm{~h}$, de Janeiro, correspondem a $82 \%$ do máximo mensal ocorrido na série centenária de referência e os valores relativos dos restantes meses ficam aquém de $60 \%$ dos máximos extremos, e significativamente abaixo do valor máximo até agora registado no IGU, de $122.7 \mathrm{~mm}$ em $24 \mathrm{~h}$, registados em Setembro de 1936.

Relativamente aos máximos de precipitação acumulada em 1hora, os valores sãode, por ordem decrescente, $17.7 \mathrm{mmemFevereiro,} 15.1 \mathrm{~mm}$ em Novembro, $13.2 \mathrm{~mm}$ em Janeiro, $12.4 \mathrm{~mm}$ em Março, $11.1 \mathrm{~mm}$ em Dezembro e $9.0 \mathrm{~mm}$ em Outubro. Só os valores observados nos meses de Fevereiro e de Janeiro não ficam muito aquém dos máximos extremos registados, para esses meses, no período de 1891-1990, correspondendo- ihes valores relativos de $82 \%$ em Fevereiro e $71 \%$ em Janeiro. Os valores relativos dos restantes meses não ultrapassam os $60 \%$ dos máximos extremos da série secular. No entanto, qualquer um destes valores máximos horários de precipitação ocorridos em cada um dos meses do semestre Outubro-Março de 2000/ 12001 , são muito inferiores (menos de $41 \%$ ) ao valor recorde registado no IGU: $43.0 \mathrm{~mm}$ em $1 \mathrm{~h}$, em Junho de 1950.

Se a quantidade de precipitação acumulada e o numero de dias de precipitação foram muito elevados, a intensidade das precipitações não foi particularmente significativa. A contextualização das precipitações nos correspondentes regimes pluviométricos prováveis, porém, torna mais claros os valores comentados.

\section{Contextualização do semestre Outubro-Março 2000/2001 relativamente ao regime pluviomé- trico "provável"}

Oquadro 3 apresenta as probabilidades de ocorrência mensal de um número de dias de precipitação superior à observada em 2000/2001, tendo como base o regime provável calculado para a série secular de referência 1891-1990, no IGU de Coimbra. De acordo com estes resultados, o número de dias de precipitação registados em Outubro e em Fevereiro ficaram aquém do valor mediano e as probabilidades de ocorrência de um numero de dias de precipitação superior ao que ocorreu em 2000/2001 são, respectivamente de $65 \%$ e de $60 \%$. Porém, relativamente aos restantes meses deste semestre pluvioso, as probabilidades de ocorrência de um maior número de dias de precipitação do que a que se verificou, são de $15 \%$ em Janeiro, $5 \%$ em Novembro, $4 \%$ em Dezembro e de apenas $1 \%$ em Março. Quer dizer que, em relação à série centenária de referência, o número de dias em que ocorreu precipitação, em Março, ficou muito próximo do valor recorde, mas em nenhum dos meses se atingiram valores extremos, embora relativamente próximos dos máximos extremos.

Os quadros 4 e 5 são complementares. No quadro 4 os valores de precipitação acumulada mensal, de precipitação máxima em $12 \mathrm{~h}$ e em $1 \mathrm{~h}$, ocorridos no semestre Outubro-Março de 2000/2001, contextualizam-se no regime provável baseado nos decís das séries das variáveis calculados para o período de 1891-1990. A contextualização intra-decílica pode ter uma leitura, por aproximação, em termos de probabilidades de ocorrência de valores das mesmas variáveis, superiores aos valores ocorridos no semestre pluvioso em análise, e que se apresentam no quadro 5.

Assim, relativamenteà precipitação mensal acumulada $(0-24 \mathrm{~h})$, nos meses menos pluviosos, Outubro e Fevereiro, a quantidade de chuva ocorrida situa-se entre $06^{\circ}$ e $07^{\circ}$ decíl, oque aponta para probabilidades destes valores de precipitação serem ultrapassados de 30 a $40 \%$. Não se trata, portanto, de valores extraordinários de precipitação, como os acumulados nos meses de Novembro, Dezembro, Janeiro e Março, acima do $9^{\circ}$ decíl, por isso, com probabilidades de ocorrência inferior a $10 \%$.

Quanto aos máximos de precipitação ocorrida em 24h, só no caso dos meses de Janeiro e de Fevereiro os valores observados ficam acima do $9^{\circ}$ decíl, logo com probabilidades de ocorrência inferiores a 10\%. A mesma variável, para Novembroe Dezembro, situa-se entre o $8^{\circ}$ e o $9^{\circ}$ decíl, com probabilidades de ocorrência entre 10 e $20 \%$, e para os meses de Outubro e Março, entre o $7^{\circ}$ e o $8^{\circ}$ decíl, podendo, portanto, ocorrer valores de precipitação máxima em $24 \mathrm{~h}$, mais elevados, com 20 a $30 \%$ de probabilidades. 
O máximo pluviométrico ocorrido em $1 \mathrm{~h}$, no mês de Outubro, ficou aquém do valor mediano, situando-se entre o $4^{\circ}$ e o $5^{\circ}$ decíl, com probabilidades de ocorrência de valores superiores de 50 a $60 \%$, e no mês de Dezembro, entre o $7^{\circ}$ e o $8^{\circ}$ decíl, podendo ocorrer valores superiores de precipitação em $1 \mathrm{~h}$ com 20 a $30 \%$ de probabilidades. Já em Novembro, Janeiro, Fevereiro e Março, os valores máximos de chuva acumulada em $1 \mathrm{~h}$ ultrapassam o $9^{\circ}$ decíl, o que os situa num contexto de probabilidades de ocorrência inferior a $10 \%$, portanto, muito próximos dos valores recorde da série de referência de 1891-1990, sem que estes, no entanto, tenham sido atingidos.

\section{Conclusão}

A análise mensal das variáveis consideradas número de dias de precipitação, precipitação acumulada, precipitação máxima em 24 h e precipitação máxima em 1 h - no semestre Outubro-Março de 2000/2001, e sua con textualização nos regimes médios e prováveis na estação meteorológica do IGU, mostra que, muito embora se tenha tratado de um período de elevados quantitativos pluviométricos, porém, não foram atingidos valores recordes de precipitação. Pelo menos em Coimbra e quando analisados os dados, mês a. mês, e tendo como base uma série centenária de referência (1891-1990), previamente estudada. Noentanto, os valores de algumas destas variáveis foram, nalguns casos, anteriormente dissecados, muito próximos dos valores extremos registados no período de referência.

Considerando-se os valores de precipitação acumulada de 1 de Outubro de 2000 a 31 de Março de 2001 , bem como o número total de dias em que ocorreu precipitação neste semestre, e comparandose os resultados com os valores observados no IGU desde que há registos (1876 para a precipitação acumulada e 1865 para o número de dias de precipitação), numa análise retrospectiva hierárquica decrescente desde os máximos extremos, obtêm-se os resultados apresentados no quadro 6 , que sintetizam a intensidade do paroxismo pluviométrico "invernal" de 2000/2001.

O semestre Outubro-Março mais chuvoso de que há registos em Coimbra (IGU), foi o de 1935/36, quer em precipitação acumulada, com $1378.2 \mathrm{~mm}$, quer em número de dias de chuva, com 126 dias. O semestre Outubro-Março de 2000/2001 aparece como o segundo mais chuvoso, em quantidade de precipitação

\begin{tabular}{|c||c|c|c|c|c|c|}
\hline $\begin{array}{c}\text { Prec. } \\
\mathbf{n}^{\mathbf{0}} \text { dias }\end{array}$ & Out & Nov & Dez & Jan & Fev & Mar \\
\hline \hline Probabilidades (\%) & 65 & 5 & 4 & 15 & 60 & 1 \\
\hline
\end{tabular}

Quadro 3 - Probabilidades de ocorrência mensal de um $n^{\circ}$ de dias de precipitação superior à observada em 2000/2001, com base no regime provável calculado para a série secular de referência 1891-1990, em Coimbra (IGU)

\begin{tabular}{|c|c|c|c|c|c|c|c|}
\hline \multirow{3}{*}{$\begin{array}{r}\text { Quadro } 4 \text { - Contextualização intra-decílica } \\
\text { de parâmetros pluviométricos mensais de } \\
2000 / 2001 \text { relativamente aos respectivos } \\
\text { regimes prováveis calculados para a série } \\
\text { secular de referência } 1891-1990 \text {, em } \\
\text { Coimbra (IGU) }\end{array}$} & Decís & Out & Nov & Dez & Jan & Fev & Mar \\
\hline & $\begin{array}{c}\text { Prec. acumulada } \\
(0-24 h)\end{array}$ & & & & $>$ D9 & D6/D7 & $>\mathrm{D} 9$ \\
\hline & $\begin{array}{l}\text { Prec. máxima em } 24 \mathrm{~h} \\
\text { Prec. máxima em 1h }\end{array}$ & $\begin{array}{l}\text { D7/D8 } \\
\text { D4/D5 }\end{array}$ & $\begin{array}{l}\text { D8/D9 } \\
>\text { D9 }\end{array}$ & $\begin{array}{l}\text { D8/D9 } \\
\text { D7/D8 }\end{array}$ & $\begin{array}{l}>\mathrm{D} 9 \\
>\mathrm{D} 9\end{array}$ & $\begin{array}{l}>\mathrm{D} 9 \\
>\mathrm{D} 9\end{array}$ & $\begin{array}{l}\mathrm{D} 7 / \mathrm{D} 8 \\
>\mathrm{D} 9\end{array}$ \\
\hline
\end{tabular}

\begin{tabular}{|c||c|c|c|c|c|c|}
\hline $\begin{array}{c}\text { Probabilidades } \\
\text { \% }\end{array}$ & Out & Nov & Dez & Jan & Fev & Mar \\
\hline \hline $\begin{array}{c}\text { Prec. acumulada } \\
\begin{array}{c}\text { (0-24h) } \\
\text { Prec. máxima em 24h } \\
\text { Prec. máxima em 1h }\end{array}\end{array}$ & $\begin{array}{c}20-30-40 \\
50-60\end{array}$ & $\begin{array}{c}10-20 \\
<10\end{array}$ & $\begin{array}{c}10-20 \\
20-30\end{array}$ & $\begin{array}{c}<10 \\
<10\end{array}$ & $\begin{array}{c}<10 \\
<10\end{array}$ & $\begin{array}{c}20-30 \\
<10\end{array}$ \\
\hline
\end{tabular}

Quadro 5 - Probabilidades de ocorrência mensal de valores de parâmetros pluviométricos superiores aos observados em 2000/2001, com base nos respectivos regimes prováveis calculados para a série de referência 1891-1990, em Coimbra (IGU)

\begin{tabular}{|c|c|c|c|c|}
\hline & $\begin{array}{l}\text { Prec. acum. } \\
\text { Out-Mar }\end{array}$ & Anos & $\begin{array}{l}\text { Prec. } \mathbf{n}^{\mathbf{0}} \text { dias } \\
\text { Out-Mar }\end{array}$ & Anos \\
\hline & 1378.2 & $1935 / 36$ & 126 & $1935 / 36$ \\
\hline & 1365.3 & $2000 / 2001$ & 122 & $1965 / 66$ \\
\hline & 1247.6 & $1976 / 77$ & 120 & $2000 / 2001$ \\
\hline & 1204.4 & $1965 / 66$ & 117 & $1976 / 77$ \\
\hline $\begin{array}{r}\text { Quadro 6 - Contextualização da precipitação acumulada } \\
\text { (0-24h) e do }{ }^{\circ} \text { de dias com precipitação } \geq 0.1 \mathrm{~mm} \text {, na } \\
\text { seriação dos } 5 \text { semestres Outubro-Março mais pluviosos } \\
\text { desde que há registos* em Coimbra (IGU) }\end{array}$ & 1165.1 & $1959 / 60$ & 116 & $\begin{array}{l}1911 / 12 \\
1959 / 60 \\
\end{array}$ \\
\hline
\end{tabular}


acumulada, com $1365.3 \mathrm{~mm}$, e em terceiro lugar em número de dias de precipitação, com 120 dias, logo a seguir a $1965 / 66$, no qual ocorreram apenas mais 2 dias. O mesmo semestre, mas de 1976/77, que aparece como o terceiro mais pluvioso desde que "há memória", acumulou uma precipitação de $1247.6 \mathrm{~mm}$, menos $117.7 \mathrm{~mm}$ do que o de 2000/2001. Este será o número com maior significado para a caracterização do paroxísmo pluviométrico de 2000/2001. Não foi - mais chuvoso da "história pluviométrica" de Coimbra...mas foi quase!

\section{Bibliografia}

ALVES, A. (2001) - "Istabilidade e Risco Geomorfológico. Deslizamento na Serra da Alrota - Bucelas/Loures, Janeiro 2001". Revista Técnica e Formativa, Escola Nacional de Bombeiros, ano 5, $\mathrm{n}^{\circ}$ 17, pp. 17-24.
GANHO, N. (1998) - O Clima Urbano de Coimbra. Estudo de Climatologia local aplicada ao ordenamento urbano. I.E.G. e C.E.G.C., Coimbra, 55 lp. (policopiado).

LEMOS, L.; LOURENÇO, L. e GONÇALVES, C. (2001) "Movimentos em Massa. Exemplos no Centro de Portugal". Revista Técnica e Formativa, Escola Nacional de Bombeiros, ano $5, \mathrm{n}^{\circ} 18$, pp. 17-41.

LOURENÇO, L. e LEMOS, L. (2001) - "Considerações acerca da movimentação em massa ocorrida na vertente poente da $\mathrm{Av}$. Elísio de Moura, em Coimbra". Territorium, n 8, pp. 93-108.

PEDROSA, A., LOURENÇO, L. e FELGUEIRAS, J. (2001) "Movimentos em Massa. Exemplos ocorridos no Norte de Portugal". Revista Técnica e Formativa, Escola Nacional de Bombeiros, ano 5, $\mathrm{n}^{\circ}$ 17, pp. 25-39.

REBELO, F. (2001) - "Os Movimentos em Massa na Perspectiva da Teoria do Risco". Revista Técnica e Formativa, Escola Nacional de Bombeiros, ano 5, $\mathrm{n}^{\circ} 17, \mathrm{pp} .7-16$. 
